\title{
Salivary cortisol level and uncooperative behavior in pediatric dental practice
}

\author{
Ludmila Tavares Costa Ercolin', Gláucia Maria Bovi Ambrosano', Livia Fernandes Probst', \\ Margarete C. Ribeiro-Dasilva ${ }^{2}$, Scott L. Tomar ${ }^{2}$, Rosana de Fátima Possobon ${ }^{1}$ \\ ${ }^{1}$ Universidade Estadual de Campinas - UNICAMP, Piracicaba Dental School, Department of Community Dentistry, Piracicaba, SP, Brazil \\ 2University of Florida, College of Dentistry, Department of Community Dentistry \& Behavioral Science, Gainesville, FL, United States of America
}

\begin{abstract}
Aim: To investigate the relation between uncooperative behavior and salivary cortisol level in children who underwent preventive dental care. Methods: The sample was composed by 10 children of both sexes aged 40 to 52 months, presenting uncooperative behavior during dental preventive treatments. The saliva collection was performed using a cotton wheel and an Eppendorf tube (Sarstedt Salivete ${ }^{\circledR}$ ) in 3 different moments: a) at home, on a day without dental treatment and at the same time on the day of the sessions treatment; b) 30 min after the end of the session, when there was manifestation of uncooperative behavior; c) $30 \mathrm{~min}$ after the end of the session, when there was a cooperative behavior of the child. A sample of saliva was centrifuged for 5 minutes at $2400 \mathrm{rpm}, 1$ of $\mathrm{mL}$ of saliva was pipetted in an Eppendorf tube and stored in a freezer at $-20^{\circ} \mathrm{C}$. For the determination of the levels of salivary cortisol was used an Active ${ }^{\circledR}$ kit for cortisol enzyme immunoassay (EIA) DSL-1067100 , composed of specific rabbit antibody anti-cortisol. Data were analyzed statistically for the uncooperative behavior issued in the beginning and at the end of sessions, using the paired $t$ test $(p<0.05)$ and for cortisol levels in saliva samples at home, after the beginning and at the end of sessions, using repeated-measures ANOVAand Tukey's test $(p<0.05)$. Results: During expression of uncooperative behavior in preventive dental care sessions the salivary cortisol level was significantly higher $(0.65 \pm 0.25 \mu \mathrm{g} / \mathrm{dL})$ compared with expression of collaborative behavior $(0.24 \pm 0.10 \mu \mathrm{g} / \mathrm{dL})$. Conclusions: It is possible to conclude that, even under preventive intervention, the stress must be controlled in order to reduce dental anxiety and fear.
\end{abstract}

Keywords: Dental Anxiety. Salivary Elimination. Dental Care.

\section{Introduction}

Anxiety and stress are deeply related to dental treatment. Behaviors such as avoidance or escape during the treatment are commonly expressed by anxious patients, representing a barrier to receiving dental care, even when very necessary, compromising the individual oral health ${ }^{1,2}$.

Received for publication: July 14, 2016 Accepted: August 02, 2016

Correspondence to: Rosana de Fátima Possobon Faculdade de Odontologia de Piracicaba - UNICAMP

Av. Limeira, $901-$ cp.52

CEP: $13414-903-$ Piracicaba - SP - Brasil Phone: +55 1921065275 - Fax: +55 1921065218 E-mail: possobon@fop.unicamp.br
Indeed, dental pediatric patients have no choice when they are taken by parents for dental treatment ${ }^{3}$. Thus, children usually express their fears through behavior such as crying, refusal to open the mouth and physical aggression in an attempt to avoid the dental care ${ }^{4,5}$.

In some cases, the child is referred to the dental office with a condition that does not require oral curative intervention but, even if only preventive procedures are attempted with low potential for generating pain and discomfort, manifesting a behavior of uncooperative with treatment. This experience can be very stressful for both, the dentist, children and their caregivers ${ }^{6}$. 
Some studies suggest that about $25 \%$ of children have bad behavior in the dental chair, which must be managed to ensure a minimum of technical quality of treatment ${ }^{7,8}$. In these circumstances, the professional must use strategies to teach children how to behave during the session, to minimize the aversive situation ${ }^{5}$.

Besides the observation of behavioral manifestations, an objective way to investigate the presence of stress is by measuring the levels of salivary cortisol, which usually change about $30 \mathrm{~min}$ after a stressor stimulus due to the activation of the hypothalamic-pituitary-suprarenal ${ }^{9,10}$.

The involvement of glucocorticoids in the stress reaction was evidenced by Selye ${ }^{11}$ (1936) that focused on the pituitaryadrenocortical axis as the effectors of this response. In humans, at least $95 \%$ of glucocorticoid activity of adrenal-cortical secretions is attributed to the cortisol hormone, also known as hydrocortisone, and its fundamental role in stress response been recognized ever since ${ }^{12,13}$.

The plasma analysis of cortisol is considered a fair biomarker indicator of stress induced by the activity of the hypothalamic-pituitary-adrenal ${ }^{14}$. The assessment of cortisol in saliva is correlated positively with its blood concentration, reflecting about 5 to $10 \%$ of serum concentration ${ }^{15}$ and can perfectly substitute plasma for analysis.

The salivary measure concentration of cortisol is technically simple, effective, noninvasive, free of stress, which is independent of salivary flow and fluctuations of transcortine with great potential for application ${ }^{16,17}$.

Kandemir et al. ${ }^{18}$ (1997) evaluated the level of salivary cortisol in children who had never had previous dental experience and concluded that the situation of curative treatment can be stressful for these patients. Akyuz, Pince and Hekin ${ }^{19}$ (1996) showed that there is an increased level of children salivary cortisol passing through dental restorative procedures. The authors reported that cavity preparation was the procedure with greater stressor potential among children in their sample. However, there are no reports of such scientific research related to non-invasive dental procedures. Therefore, this study investigated the level of salivary cortisol among children undergoing preventive dental treatment.

\section{Material and methods}

The study design was reviewed and approved by the Committee on Human Research from Piracicaba Dental School - State University of Campinas, under the protocol: $124 / 2005$. The sample were composed by 10 children of both sexes aged 40 to 52 months, presenting uncooperative behavior during dental preventive treatments (removal of dental biofilm, brushing training done by the mother and the dentist, and clinical examination).

In order to reduce children's stress and increase their cooperation, experimental sessions were planned with successive steps of approach, with presentation of clinical procedures and gradual invasiveness. Thus, respecting the pace of each child, the dentist showed the brushing technique on a dummy, took the child to the sink to brush his/her own teeth, applied a colorful plaque disclosing agent, brush the child's teeth, led him/her to the dental chair to conduct the clinical examination using intraoral mirror and air jet under reflector light and prophylaxis with pumice and rotating Robson brushes. During these sessions, the dentist employed behavior management strategies, such as distraction (songs and stories) and positive reinforcement (with compliments and gifts $)^{5}$.

All sessions were filmed and subsequently examined to determine uncooperative behaviors of the children (crying, movements of body and head in order to prevent or stop the procedure and verbal refusal). The researchers divided the total session time at intervals of $15 \mathrm{~s}$ and recorded all behaviors expressed during each interval.

The saliva collection was performed using a cotton wheel and a tube of the type Eppendorf (Sarstedt Salivete ${ }^{\circledR}$ ) at 3 moments: a) the child's at home, on a day without dental treatment and at the same time on the day of the treatment sessions, b) 30 min after the end of the session, when there was manifestation of uncooperative behavior, c) $30 \mathrm{~min}$ after end of the session, when there was the collaboration of the child. These sessions were always scheduled in the afternoon to avoid the influence of circadian cycle on the cortisol secreted level.

A sample of saliva was centrifuged for $5 \mathrm{~min}$ at $2400 \mathrm{rpm}$, $1 \mathrm{~mL}$ was pipetted saliva in an Eppendorf tube and stored in a freezer at $-20{ }^{\circ} \mathrm{C}$. For the determination of the levels of salivary cortisol was used an Active ${ }^{\circledR}$ kit for cortisol enzyme immunoassay (EIA) DSL-10-67100, composed of specific rabbit antibody anti-cortisol. The procedure followed the basic principle of enzyme immunoassay where there is a competition between an antigen enzyme not labeled with a certain number of antibody binding sites.

The amount of antigen labeled with enzyme is inversely proportional to the concentration of analyte present unchecked. The unbound material is removed by decanting and washing the cavities. The absorbance of the solution was read in an ELISA microplate reader with $450 \mathrm{~nm}$ and the ability to fix the double wavelength adjusted to $600 \mathrm{~nm}$.

Data were analyzed statistically for the uncooperative behavior issued in the beginning and at the end of sessions, using the paired t test $(\mathrm{p}<0.05)$ and for cortisol levels in saliva samples at home, after the beginning and at the end of sessions, using repeated-measures ANOVA and Tukey's test $(\mathrm{p}<0.05)$.

\section{Results}

Statistically significant differences were found between the average of the absolute frequency of uncooperative behavior by the children during the beginning and at the end of session (Table 1).

The level of salivary cortisol also showed significant variation among the collections made at home, after the beginning and at the end of sessions (Table 2).

The relationship between the salivary cortisol level and the frequency of uncooperative behavior can be verified in Figure 1. This figure shows that in child presenting aversion to treatment, 
the salivary cortisol level were higher when compared to session in which the child cooperated.

Table 1 - Absolute frequency average and standard deviation of uncooperative behavior by the children during the beginning and at the end of intervention session.

\begin{tabular}{lc}
\hline Session & Frequency of behaviors per intervention \\
Beginning & $44.6 \pm 16.72 \mathrm{~A}$ \\
End & $5.40 \pm 3.92 \mathrm{~B}$ \\
\hline
\end{tabular}

Averages followed by different letters differ vertically by paired T-test $(p<0.05)$.

Table 2 - Salivary cortisol levels ( $\mu \mathrm{g} / \mathrm{dL}$ ) averages and standard deviations from collections made in the child's home, after the beginning and at the end of dental intervention session.

\begin{tabular}{lc}
\hline Session & Salivary cortisol level \\
Home & $0.22 \pm 0.11 \mathrm{~A}$ \\
Beginning & $0.65 \pm 0.25 \mathrm{~B}$ \\
End & $0.24 \pm 0.10 \mathrm{~A}$ \\
\hline
\end{tabular}

Averages followed by different letters in the vertical differ by Tukey test $(p<0.05)$.

\section{Discussion}

The determination of salivary cortisol has been evaluated in relation to deprivation of sleep in patients who are night workers ${ }^{20}$, in patients with chronic fatigue ${ }^{21}$ and for assessment of stress during dental treatment in adults ${ }^{22,24}$. However, few studies have evaluated the stress related to levels of cortisol among children in the dental situation, and those who have been, investigated the reaction of child during curative treatment ${ }^{18,19}$. These studies indicated that some invasive procedures, such as oral anesthesia, cavity preparation with high-speed handpiece and third molar extraction surgery are stressful for patients, with significant variation in salivary cortisol levels before and after the intervention.

Studies on the behavioral manifestations of the child in fearful dental situation also highlight certain clinical procedures as more aversive suggesting psychological approaches and/or pharmacological intervention to decrease patient stress $5,6,25,26$. However, as studies with determination of salivary cortisol ${ }^{18,19}$, this work investigated the conduct issued by children exposed only to the healing of dental treatment. This seems to be due to the fact that non-cooperation is a greater challenge than the curative action of preventive dentistry-whose performance depends directly on the clinical behavior of the patient.

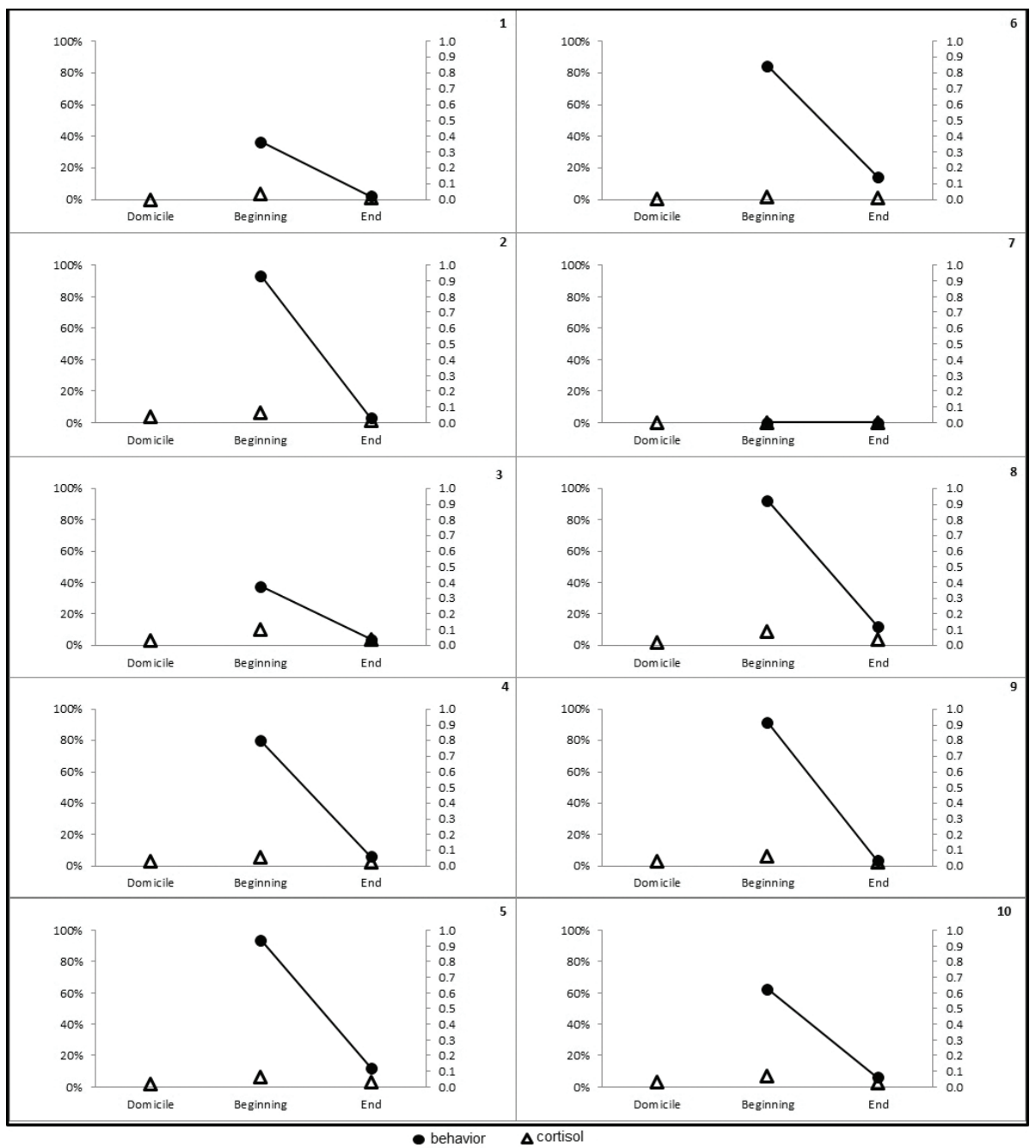

Fig.1. Immunohistochemical expression of TIMP-2 / OSCC negative control. 
This study showed that child who exhibit uncooperative behavior, or express fear of dental treatment, by crying or refusal to allow the dentist actions, also show high levels of cortisol in the context of preventive dental treatment. Simple and less invasive, such as application of dye biofilm-brushing and clinical survey can trigger child fearful stress reactions. Several authors have reported that stress in patients leads to the manifestation of non-cooperation pediatric dentistry behavior that hinder or prevent the completion of dental procedures ${ }^{27}$.

Some authors suggest that fearful children have often a painful history of treatments and/or unpleasant events in their first visits to the dentist ${ }^{26-28}$. The children in this study had not experienced dental curative treatments, but they had been exposed several times to preventive procedures. However, the children were not adapted to routine dental care because the goal in this study was to perform the preventive dental procedures and not to decrease the dental fear.

As Possobon et al. ${ }^{27}$ (2007) claim, when the professional is basically focused on technical procedures, child manifestation of fear and stress may not be noted or understood, depriving the necessary physiological support to the patient. The authors state that dental professionals might implement strategies to identify and then minimize the stress commonly generated by dental intervention, monitoring behaviors indicative of stress.

Thus, during the experimental sessions, in which psychological strategies were employed for managing behavior, there was a gradual decrease in the frequency of children's behavior, and at the same time, a reduction in salivary cortisol level was noted, showing the relationship between behavioral and physiological manifestations of stress.

Even though curative interventions might eventually be necessary, preventive procedures must occur periodically over a child's life. Therefore, dentists must adopt measures to manage behaviors indicative of stress and anxiety in order to reduce escape and avoidance from routine dental visits ${ }^{29}$, allowing a good quality of intervention and also preventing unnecessary stressful situations to children.

\section{References}

1. Appukuttan DP. Strategies to manage patients with dental anxiety and dental phobia: literature review. Clin Cosmet Investig Dent. 2016 Mar 10;8:35-50. doi: 10.2147/CCIDE.S63626.

2. Milgrom P, Newton JT, Boyle C, Heaton LJ, Donaldson N. The effects of dental anxiety and irregular attendance on referral for dental treatment under sedation within the National Health Service in London. Community Dent Oral Epidemiol. 2010 Oct;38(5):453-9. doi: 10.1111/j.1600-0528.2010.00552.x.

3. Armfield JM, Heaton LJ. Management of fear and anxiety in the dental clinic: a review. Aust Dent J. 2013 Dec;58(4):390-407; quiz 531. doi: 10.1111/adj.12118.

4. Possobon RF, Caetano MES, Moraes ABA. [Dental treatment of uncooperative children: a case report]. Rev Bras Odontol. 1998;55(2):80-3. [Portuguese].

5. Possobon RF. [Effects of diazepam on no-collaborative behavior of children in dental care] [tese]. Piracicaba: Faculdade de Odontologia de Piracicaba/Unicamp; 2003. [Portuguese]

6. Wright GZ, Kupietzky A. Behavior management in dentistry for children. John Wiley \& Sons; 2014

7. Wilson S, Thikkurissy S, Gosnell ES. Behavior and the Child. In: Oral Sedation for Dental Procedures in Children. Springer Berlin Heidelberg. 2015. p.7-24.

8. Polk DE, Nolan BA, Shah NH, Weyant RJ. Policies and Procedures That Facilitate Implementation of Evidence-Based Clinical Guidelines in U.S. Dental Schools. J Dent Educ. 2016 Jan;80(1):23-9

9. Jessop DS, Turner-Cobb JM. Measurement and meaning of salivary cortisol: A focus on health and disease in children. Stress, 2008 Jan;1(1)1-14. Epub 2007 Jul 16.

10. Blomqvist M, Holmberg K, Lindblad F, Fernell E, Ek U, Dahllof G. Salivary cortisol levels and dental anxiety in children with attention deficit hyperactivity disorder. Eur J Oral Sci 2007 Feb;115(1):1-6.

11. Selye H. A syndrome produced by diverse noccious agents. Nature. 1936 July 4;138(3479):32.

12. Quinkler M, Beuschlein F, Hahner S, Meyer G, Schöfl C, Stalla GK. Adrenal cortical insufficiency-a life threatening illness with multiple etiologies. Dtsch Arztebl Int. 2013 Dec 23;110(51-52):882-8. doi: 10.3238/arztebl.2013.0882.

13. Buchanan TW, Brechtel A, SollersIll JJ, Lovallo WR. Exogenous cortisol exerts effects on the startle reflex independent of emotional modulation. Pharmacol Biochem Behav. 2001 Feb;68(2):203-10.

14. Petrakova L, Doering BK, Vits S, Engler H, Rief W, Schedlowski M, et al. Psychosocial Stress Increases Salivary Alpha-Amylase Activity Independently from Plasma Noradrenaline Levels. PLoS One. 2015 Aug 6;10(8):e0134561. doi: 10.1371/journal.pone.0134561.

15. Ponzi D, Muehlenbein MP, Sgoifo A, Geary DC, Mark V. Day-to-day Variation of Salivary Cortisol and Dehydroepiandrosterone (DHEA) in Children from a Rural Dominican Community Flinn. Adapt Human Behav Physiol. 2015 Mar;1(1):4-16.

16. Antonini SR, Jorge SM, Moreira AC. The emergence of salivary cortisol circadian rhythm and its relationship to sleep activity in preterm infants. Clin Endocrinol 2000 Apr;52(4):423-6.

17. Blomqvist M, Holmberg K, Lindblad F, Fernell E, Ek U, Dahllöf G. Salivary cortisol levels and dental anxiety in children with attention deficit hyperactivity disorder. Eur J Oral Sci. 2007 Feb;115(1):1-6.

18. Kandemir S, Oksan T, Alpoz AR, Ergezer Z, Kabalak T. Salivary cortisol levels in children during dental treatment. J Marmara Univ Dent Fac 1997 Sep;2(4):639-42.

19. Akyuz S, Pince S, Hekin N. Children's stress during a restorative dental treatment: assessment using salivary cortisol measurements. J Clin Pediatr Dent 1996 Spring;20(3):219-23.

20. Lac G, Chamoux A. Elevated salivary cortisol levels as a result of sleep deprivation in a shift worker. Occup Med (Lond) 2003 Mar;53(2):143-5.

21. Gaab J, Huster D, Peisen R, Engert V, Heitz V, Schad T et al. Assessment of cortisol response with low-dose and high-dose ACTH in patients with chronic fatigue syndrome and healthy comparison subjects. Psychosomatics 2003 Mar-Apr;44(2):113-9.

22. Hill CM, Walker RV. Salivary cortisol determinations and self-rating scales in the assessment of stress in patients undergoing the extraction of wisdom teeth. Br Dent J 2001 Nov 10;191(9):513-5.

23. Kruerge TH, Heller HW, Hauffa BP, Haake P, Exton MS, Schedlowski $M$. The dental anxiety scale and effects of dental fear on salivary cortisol. Percept Mot Skills 2005 Feb;100(1):109-17. 
24. Greabu M, Purice M, Totan A, Spinu T, Totan C. Salivary cortisolmarker of stress response to different dental treatment. Rom J Intern Med 2006;44(1):49-59.

25. Milgrom P, Fiset L, Melnick S, Weinstein P. The prevalence and practice management consequences of dental fear in a mayor U.S. City. J Am Dent Asoc. 1988 May;116(6):641-7.

26. Townend E, Dimigen G, Fung D. A clinical study of child dental anxiety. Behav Res Ther. 2000 Jan;38(1):31-46.
27. Possobon RF, Carrascoza KC, Moraes ABA, Costa Jr AL. [Dental treatment as a cause of anxiety]. Psicol Estud. 2007 Sep/ Dec;12(3):609-16. [Portuguese].

28. Liddell A, Gosse V. Characteristics of early unpleasant dental experiences. J Behav Ther Exp Psychiatry. 1998 Sep;29(3):227-37.

29. Fioravante DP, Soares MRZ, Silveira JM, Zakir NSA. [The patientprofessional relationship functional analysis in the pediatric dentistry. Estud Psicol. 2007 Apr/Jun;24(2):267-77. [Portuguese]. 